\title{
Erratum to: Middleware 2009
}

\author{
Jean M. Bacon ${ }^{1}$ and Brian F. Cooper ${ }^{2}$ \\ 1 Computer Laboratory, University of Cambridge, William Gates Building, \\ JJ Thomson Avenue, Cambridge, CB3 0FD, UK \\ jmb25@cl.cam.ac.uk \\ 2 Yahoo! Research, 4401 Great America Parkway, Santa Clara, CA 95054, USA \\ cooperb@yahoo-inc.com
}

\section{Erratum to: \\ J.M. Bacon and B.F. Cooper (Eds.) \\ Middleware 2009 \\ DOI: $10.1007 / 978-3-642-10445-9$}

The book was inadvertently published with an incorrect name of the copyright holder. The name of the copyright holder for this book is: (c) IFIP International Federation for Information Processing. The book has been updated with the changes.

The updated original online version for this book can be found at DOI: $10.1007 / 978-3-642-10445-9$ 